This item was submitted to Loughborough's Research Repository by the author.

Items in Figshare are protected by copyright, with all rights reserved, unless otherwise indicated.

\title{
The role of working hours, work environment and physical leisure activity on the need for recovery following a day's work among UK white-water raft guides: a within-subjects multilevel approach
}

\section{PLEASE CITE THE PUBLISHED VERSION}

http://dx.doi.org/10.1016/j.psychsport.2015.12.004

\section{PUBLISHER}

(c) Elsevier Ltd

\section{VERSION}

AM (Accepted Manuscript)

\section{PUBLISHER STATEMENT}

This work is made available according to the conditions of the Creative Commons Attribution-NonCommercialNoDerivatives 4.0 International (CC BY-NC-ND 4.0) licence. Full details of this licence are available at: https://creativecommons.org/licenses/by-nc-nd/4.0/

\section{LICENCE}

CC BY-NC-ND 4.0

\section{REPOSITORY RECORD}

Wilson, lain S., Hilary McDermott, and Fehmidah Munir. 2019. "The Role of Working Hours, Work Environment and Physical Leisure Activity on the Need for Recovery Following a Day's Work Among UK White-water Raft Guides: A Within-subjects Multilevel Approach". figshare. https://hdl.handle.net/2134/20068. 
1 The role of working hours, work environment and physical leisure activity on the need

2 for recovery following a day's work among UK white-water raft guides: A within-

3 subjects multilevel approach.

4

5 Published in: Psychology of Sport and Exercise 23:123-131 01 Mar 2016

6 Accepted peer-reviewed version

7

8 Iain Wilson, Hilary McDermott, Fehmidah Munir

9

$10{ }^{1}$ Sports Psychology Research Group, School of Sport, Exercise and Health Sciences,

11 Loughborough University, Loughborough, Leicestershire, LE11 3TU. England

12

13

$14 \quad$ I.S.Wilson@lboro.ac.uk

$15 \quad$ H.J.McDermott@lboro.ac.uk

$16 \quad$ F.Munir@lboro.ac.uk

17

18

19

$20 *$ Corresponding author. Tel +44 (0)7746 333507; Fax N/A.

21 E-mail address: I.S.Wilson@lboro.ac.uk

22

23 
Abstract

26 Background: White-water raft guides are a growing workforce of the outdoor sector but little

27 is known about how the working environment, workload and physical leisure activity impacts on the need for occupational recovery (the desire to replenish internal resources and recuperate in the time immediately following work) of those working in this physically demanding occupation.

31 Methods: Longitudinal data were collected across an eight month working season at three month intervals. Multilevel analyses tested the within-subject associations between work environment, hours worked and physical leisure activity had on the need for recovery. Results: Working longer across the working season and participating in more physical leisure activity were directly associated with a lower need for occupational recovery. Furthermore, working on natural rivers significantly reduced the need for recovery experienced compared to work on man-made courses. This was regardless of the number of hours of worked in these environments.

Discussion: Physical leisure activity may provide a distraction from work, allowing employees to replenish their physical and psychological energy, thus protecting themselves against work-related fatigue. The findings also expand upon the previous literature identifying that working in a natural environment reduces the risk of experiencing workrelated fatigue.

Psychological Well-Being; Need for Recovery; Hours Worked; Physical Leisure Activity; Natural Outdoor Environment; Longitudinal. 
White-water rafting is a social, commercial and competitive activity that requires

50 great physical skill in using a paddle or oar power to negotiate rivers (natural or man-made)

51 in a soft craft (British Canoe Union, 2015; International Rafting Federation, 2015). The role

52 of the raft guide is to provide an exhilarating experience, whilst maintaining the safety of

53 their clientele. The nature of this occupation is both physically and psychologically

54 demanding (Arnould \& Price, 1993). Commercial white-water rafting is growing in

55 popularity, with increasing participation reported in Europe (European Outdoor Group, 2013)

56 and the United States (Outdoor Foundation, 2013). As participation increases, there is a

57 potential for an increase in workload, in terms of the number of hours worked, undertaken by

58 the guides providing these activities. As white-water rafting is a seasonal activity (March to

59 October), the workloads may vary depending on participant demand, with the greatest

60 workload occurring during the peak of the season in Europe (June to August).

61 Anecdotal evidence suggests that workers in the Outdoor Industry work long hours and take little time for rest and recovery, especially as some engage in physical leisure activities which are similar to their work (Adventure Activities Industry Advisory Committee

64 [AAIAC], 2006). Empirical evidence has supported this indicating that Mountain Leaders

65 work long hours and engage in physical leisure activities on their days off, despite suffering

66 from musculoskeletal conditions and/or being tired from work (McDermott \& Munir, 2012).

67 Evidence from other types of demanding occupations have found that high work demands including long working hours and physically demanding work can lead to work-related

69 fatigue (e.g. Van Yperen \& Hagedoorn, 2003; Beckers et al., 2004). There is good evidence 70 that work-related fatigue can have further consequences on individuals' health and their 71 abilities to complete everyday activities, such as work (Mallinson, Cella, Cashy, \& Holzner, 
72 2006; de Croon, Sluiter, \& Frings-Dresen, 2003; Kant et al., 2003; Sluiter et al., 2003). So

73 far, the research has examined workers in predominantly sedentary occupations, therefore

74 little is known about the work-related fatigue of those working in physically active sporting

75 occupations, such as white-water raft guides. This study therefore explores how the working

76 hours, physical leisure activity, and working environment contribute to or protect against

77 white-water raft guides' need for occupational recovery following work across a working

78 season.

79 Conceptualising the Need for occupational recovery

80

The need for occupational recovery is a specific state of well-being which refers to the

81 short-term effects of work-related fatigue and has been conceptualised as the desire to

82 replenish internal resources and recuperate in the time immediately following work (Sluiter,

83 1999; Sluiter, de Croon, Meijman, \& Frings-Dresen, 2003). Individuals who chronically

84 recuperate insufficiently following work are more likely to develop a greater need for

85 occupational recovery (Sonnentag \& Fritz, 2007). A prolonged need for occupational

86 recovery has been associated with negative effects, such as reduced productivity at an

87 organisational level and poor health, sick leave and disability at an individual level (de Croon

88 et al., 2003; Kant et al., 2003; Sluiter et al., 2003). Furthermore, the need for occupational

89 recovery has been identified as an early indicator of chronic work-related fatigue and

90 psychological distress (Jansen, Kant, van Amelsvoort, Nijhuis, \& van den Brandt, 2003).

91 Therefore in the present study, the need for occupational recovery will be utilised as an

92 indicator of fatigue among this working population, as there is no previous literature to

93 suggest whether fatigue is a significant issue among this population.

94 A lack of psychological detachment from work has been associated with a greater

95 need for occupational recovery on a daily basis (Sonnentag \& Bayer, 2005). Individuals with 
greater workloads are more focused on their work and therefore are likely to think about their work or complete work tasks during their leisure time, resulting in impaired recovery (Sonnentag \& Bayer, 2005). Furthermore, employees with high workloads are more likely to work overtime, consider work and home activities as more effortful and report being more preoccupied with work during home time, when compared to their peers with a lower workload (van Hooff, Geurts, Kompier, \& Taris, 2007). It is therefore possible that employees who work longer hours are at risk of negative consequences, such as the development of work-related fatigue.

The relationship between the number of hours worked and health may resemble a bell curve and therefore may not be linear. Individuals who do not work enough may just be at risk of negative health consequences as those who work too much (Sparks, Cooper, Fried, \& Shirom, 1997). This may explain why not all studies have found a direct association between the number of hours worked and the need for occupational recovery after a working day (Bos, Donders, Schouteten, \& Van der Gulden, 2013; Van der Hulst, Van Veldhoven, \& Beckers, 2006). However, it could also be that these studies have only focused on non-physically active work such as university and office based administration employees. It is therefore possible that physically active work, such as white-water raft guiding, may require a greater need for occupational recovery at the end of a working day. The following hypothesis was devised to test whether the number of hours worked was linked with the need for occupational recovery among white-water raft guides:

Hypothesis Ia: A greater number of hours worked per month will be associated with a greater need for occupational recovery across a working season. Physical activity has been suggested to aid the recovery process and reduce workrelated fatigue (Korpela \& Kinnunen, 2010; Oerlemans, Bakker, \& Demerouti, 2014). This is 
120 particularly the case when individuals fully detach themselves from work and enter the great

121 outdoors (Sonnentag \& Zijlstra, 2006; Korpela \& Kinnunen, 2010). It is suggested that

122 increased time participating in outdoor activities in a natural setting helps with psychological

123 detachment and thus improves recovery (Korpela \& Kinnunen, 2010). The need for recovery

124 may also be influenced by the physical aspect of physically active jobs (Sonnentag \& Zijlstra,

125 2006). However, the relationship with work-related fatigue may be reciprocal, meaning that

126 individuals who are experiencing high levels of work-related fatigue are less likely to engage

127 in physical leisure activity (de Vries et al., 2015). This longitudinal study of Dutch workers

128 only considered physical activity during leisure time. It is unknown whether individuals

129 working in a physically active job will gain the same benefits of physical leisure activity as

130 observed in those working in sedentary occupations. The following hypothesis was therefore

131 tested:

Hypothesis Ib: A greater number of monthly hours of physical leisure activity will be associated with a lower need for occupational recovery across a working season. It is not known whether the effects of working long hours in a physically active occupation, such as white-water raft guiding, will increase or reduce work-related fatigue. As rafting can occur on a variety of bodies of water, including natural rivers and man-made course it is unknown whether being surrounded in a natural or unnatural environment will

138 affect the need for occupational recovery of white-water raft guides. Exposure to a natural 139 outdoor environment has been associated with positive physical and psychological well-being 140 (e.g. Hug, Hartig, Hansmann, Seeland \& Hornung, 2009; Cervinka, Röderer \& Hefler, 2011;

141 Nisbet, Zelenski \& Murphy, 2011). Specifically, engaging in physical activity and socialising 142 with others in a natural setting is associated with higher levels of physical and mental energy 143 (Ryan, Bernstein, Gagnè \& Brown, 2010). This has been demonstrated by the Attention 
144 Restoration Theory which poses that interactions in nature do not require directed attention,

145 thus allowing top-down directed attention abilities to replenish (Berman, Jonides \& Kaplan,

146 2008). It is important to note that all of these studies made comparisons between the benefits

147 of exposure during leisure time in nature and either an urban or indoor setting. The present

148 study will test whether the same benefits of being exposed to a natural setting during working

149 hours will have the same beneficial effects as observed during leisure time. As white-water

150 rafting is an outdoor activity which is generally not located in an urban setting, it is therefore

151 possible that raft guides who work on a natural river may experience different levels of need

152 for occupational recovery following work than those working on a man-made course. We

153 therefore proposed and tested the following hypotheses:

$154 \quad$ Hypothesis II: Working in a natural outdoor environment (i.e. on a natural river), as

155 opposed to working in an artificial environment (i.e. on a man-made course), will be

$156 \quad$ associated with a lower need for occupational recovery.

157 Hypothesis IIIa: Working longer hours on a natural river will reduce the need for

158 occupational recovery experienced, whereas working longer hours on a man-made

159 course will increase the need for occupational recovery experienced by white-water

160 raft guides.

161

Hypothesis IIIb: White-water raft guides who work on a natural river and participate

in a greater amount of physical leisure activity will experience a lower need for occupational recovery; furthermore an increased amount of physical leisure activity will reduce the need for occupational recovery experienced by those working on manmade courses. 


\section{Sample and Procedure}

A survey was utilised to collect data regarding the levels of work-related fatigue

171 among white-water raft guides working in the UK across a working season at three time

172 points (March, June and October). This study received ethical approval from Loughborough

173 University Ethical Advisory Committee.

The inclusion criteria for survey completion were participants currently employed as a

175 raft guide in the UK and aged over 18 years; and holding or working towards a relevant Raft

176 Guide Qualification e.g. BCU or International Raft Federation (IRF).

177 An online survey, designed using SurveyMonkey, was used to collect data from a

178 geographically diverse population. Early season measurements commenced in April 2013 and

179 continued until June 2013. Mid-season surveys were distributed three months after Early

180 season data collection. The final set of data collection commenced during late season, 3

181 months after mid-season collection and ceased in January 2014. A prize draw was advertised

182 as an incentive for participation retention during Mid and Late Season.

183 The survey was distributed to all 577 (357 male) qualified raft guides registered in the

184 UK via the governing body’s (Sport England, 2013) internal email. In addition, white-water

185 rafting providers were identified through the Adventure Activities Licensing Authority, and

186 contacted directly regarding the research. Individuals who started but did not complete the

187 online survey were invited by email to complete their response. Participants were requested

188 to provide a name and email to be contacted by for follow up data collection. Of the 577 raft

189 guides contacted, 126 completed the survey at baseline, a response rate of $21.84 \%$. As data

190 regarding the demographics of qualified raft guides are unavailable, other than the number of 
191 qualified males and females, it is therefore not possible to make comparisons of the

192 characteristics between completers and non-completers.

Measures

194

Need for Recovery. The Need for Recovery Scale (Veldhoven \& Broersen, 2003)

195 was utilised to assess whether a participant is recovering substantially. The scale consists of

19611 items with dichotomous responses (example items: "I find it hard to relax at the end of a 197 working day" and "I have trouble concentrating in the hours off after my working day"). Unfavourable answers score a value of one, whereas favourable answers score 0 . The total score is calculated from the sum of the scores from each item (minimum score $=0$, maximum score $=11$ ), and is then recoded into a score out of 100 . Higher scores represent a higher the need for occupational recovery which is unfavourable. Internal consistency and stability have been demonstrated for the English version of The Need for Recovery Scale (Veldhoven \& Broersen, 2003). The Chronbach's alphas for the current study were between 0.73 and 0.82 across the working season.

Other Self-Report Questions. Other self-reported measures included sex, age (years), height (metres or feet and inches) and weight (kilograms or stone and pounds) for body mass index (BMI) calculations $\left(\mathrm{kg} / \mathrm{m}^{2}\right)$, number of years' experience as a qualified white-water raft guide, type of river worked on (natural river, man-made course or a mixture of the two) and the number of working hours as a white-water raft guide and the number of

210 hours of physical leisure activity (indicated by the hours completed in a month).

\section{Strategies of Analysis}

The repeated measures design was considered to be multi-level with the measurements taken from each observation time period (Early, Mid and Late Season) being

214 nested within the individual. This creates a two-level model, with the repeated measures 
215 observations at level one ( $\mathrm{N}=3$ occasions) and the second level being the individual $(\mathrm{N}=$ 216126 participants). Multilevel analyses were conducted using the MLwiN software (Rasbash,

217 Charlton, Browne, Healy, \& Cameron, 2009). Multilevel analyses were the most appropriate for the data set obtained as there were

219 missing data due to the attrition throughout the longitudinal study. Multilevel modelling is 220 robust against missing data (Quené \& Van den Bergh, 2004) therefore all available data could 221 be included which reduces any biases in the analyses (Hill \& Goldstein, 1998). Furthermore, as the data were repeated measures in nature, observations at each time point are likely to be interdependent, i.e. not independent of each other, for example, an individual's levels of need

224 for occupational recovery measured during Early Season are likely to influence the same

225 individual's levels of need for occupational recovery during follow up measurements.

226 Independence of the variables is not assumed in multilevel analyses (Dierdorff \& Ellington, 227 2012), making this a more suitable technique than ordinary least squares (Snijders \& Bosker, 228 1994).

With regards to data manipulation, independent variables (monthly hours worked as a 230 raft guide; monthly hours of physical leisure activity) were centred for inclusion in the 231 multilevel analyses as this technique reduces the correlation between the slope and intercept 232 of the regression line thus increasing the robustness of the models assessed (Nezlek, 2001; 233 Enders \& Tofighi, 2007). As the hypotheses were concerned with the within subject 234 associations between the need for recovery experienced and hours worked or hours of 235 physical leisure activity (i.e. how the relationships vary over time), predictor variables were 236 centred on the specific mean of each participant, this is group-mean centring (Lüdtke, 237 Robitzsch, Trautwein \& Kunter, 2009). Group-mean centring (CWC) allows for the 238 disentanglement of within and between subject effects of predictors can therefore be 
239 disentangled (Lüdtke et al., 2009) thus providing a pure estimation of the within subject

240 relationships between the independent and dependent variables (Enders \& Tofighi, 2007). As

241 the hypotheses are concerned with the within subject associations (associations across time)

242 between the need for recovery and various predictor variables, group-mean centring is the

243 most appropriate technique.

244 Regarding the standardisation of data, standardising level two variables has no

245 implications regarding the coefficients produced as changing the variation in level two

246 variables also changes the standard error which is tested to determine significant results

247 (Nezlek, 2001). This is not the case for level one variables, therefore standardising level one

248 variables can result in the alteration of coefficients and their level of significance (Nezlek,

249 2001). As the present study is concerned with the within subject (Level 1) differences the

250 need for occupational recovery, data tested using the multilevel analyses were not

251 standardised.

252

Hypotheses I and II were concerned with a main effect over time. Time was therefore

253 included in the model, alongside independent variables, and was centred to baseline. To

254 assess whether the main association altered over time, an interaction term between time and

255 the independent variable (i.e. time*independent variable ${ }_{\mathrm{CwC}}$ ) was tested to see if model fit

256 improved and whether the interaction was significant.

257 Hypothesis III was concerned with the testing of moderation effects. Moderation was

258 tested using the technique described by Baron and Kenny (1986). This involves testing a

259 direct effect between the independent variable and the dependent variable (Hypothesis I).

260 Following this, a direct association between the moderator and the dependent variable is

261 tested (Hypothesis II). Finally, the independent variable and moderator are multiplied

262 together to create an interaction term; the moderation effect is tested by the association 
263 between the interaction term and the dependent variable (Hypothesis III). Time was controlled for in these analyses.

\section{Results}

\section{Description of Participants}

A total of 126 (114 male) white-water raft guides completed the survey during Early 268 Season. Participants' age ranged from 18 to 64 years $($ Mean $=30.13$, SD = 9.7). Overall, 269 participants' weight was within the normal range of Body Mass Index (Mean $=24.49$, SD $=$ 3.76). White-water rafting experience ranged from less than one year to 28 years (Mean $=$

$2715.50, \mathrm{SD}=6.20)$. Attrition was observed. A total of 98 participants completed the survey 272 during Mid-Season (attrition, 22.2\% from baseline) and 79 completed the survey during Late

273 Season (attrition, 37.3\% from baseline). The observed attrition has been considered as 274 acceptable in previous longitudinal research (Mauno, Kinnunen, \& Ruokolainen, 2007).

275 Analysis of variation tests (for continuous data) and chi square analyses (for categorical data) 276 highlighted no significant differences between the characteristics of the participants who 277 completed the survey at each time point. The only significant difference identified was 278 between the monthly number of hours worked as a raft guide, where a greater number of 279 monthly hours worked was observed during Mid-Season when compared to Early and Late 280 Season. A summary of descriptive and correlations of the nested variables can be seen in 281 Table 1.

[TABLE 1 HERE]

The first of the multilevel analyses conducted was to create an empty model, i.e. a model without any predictors, to estimate the level of variation explained of the need for occupational recovery experienced on an individual level (Level 2 variation) and over time 
in the need for occupational recovery is explained by the differences between individuals (Level 2) and that 62.54\% (396.18/[237.33+396.18]) of the variation was explained by the

differences between time points (Level 1). Following the empty model, covariates (age, body mass index and years’ experience) were included. No significant associations were observed

291 between the need for occupational recovery and age $(B=-0.03, \mathrm{SE}=0.25, \mathrm{p}=0.91)$, BMI $(\mathrm{B}$ $=0.19, \mathrm{SE}=0.69, \mathrm{p}=0.79)$, and years' experience $(\mathrm{B}=-0.08, \mathrm{SE}=0.38, \mathrm{p}=0.83)$. The inclusion of covariates did not significantly improve the model fit and $\left(X^{2}=0.17\right.$, $\mathrm{df}=3, \mathrm{p}=$ 0.98) were therefore excluded from the final analyses conducted during hypotheses testing. The coefficients from the empty model and the coefficients model can be seen in Table 2.

[TABLE 2 HERE]

297

298

299

300

301

302

303

304

305

306

307

308

309

310

\section{Results relating to Hypothesis I}

Coefficients from the multilevel analyses related to Hypothesis I are presented in

occupational recovery and the number of hours worked as a raft guide in a month. The results show that the inclusion of 'time' and 'monthly hours worked as a raft guide' explained $0.2 \%$ of the within subject variation of the need for occupational recovery and did not improve the model fit $\left(X^{2}=0.90, \mathrm{df}=2, \mathrm{p}=0.64\right)$. However, neither time $(\mathrm{B}=1.10, \mathrm{SE}=1.16, \mathrm{p}=0.34)$ nor hours worked as a raft guide $(\mathrm{B}=0.00, \mathrm{SE}=0.02, \mathrm{p}=0.86)$ were directly associated with the need for occupational recovery (See Model 1). When testing the relationship between the number of hours worked and the need for occupational recovery over time (Model 2), an additional $2.7 \%$ of the within subject variation of the need for recovery experienced was explained. Specifically, a greater number of hours worked was associated with a lower need for occupational recovery following work $(B=-0.12, \mathrm{SE}=0.05, \mathrm{p}=0.02)$ and this relationship strengthened over time $(\mathrm{B}=0.12, \mathrm{SE}=0.04, \mathrm{p}=0.003)$. 
312 leisure activity’ significantly improved the model fit $\left(X^{2}=288.68\right.$, $\left.\mathrm{df}=2, \mathrm{p}<0.001\right)$ but did

313 not explain any of the within subject variation of the need for occupational recovery (Model

314 3). A greater number of hours of physical leisure activity in a month was significantly

315 associated with a lower need for occupational recovery $(B=-0.09, \mathrm{SE}=0.04, \mathrm{p}=0.03)$.

316 Time was not associated with the need for occupational recovery $(\mathrm{B}=1.77, \mathrm{SE}=1.38, \mathrm{p}=$

317 0.20). The inclusion of the interaction between time and the number of hours of physical

318 leisure activity indicated that the relationship between monthly hours of physical leisure

319 activity and the need for occupational recovery did not alter over time $(B=0.08, S E=0.07, p$

$320=0.23)$ and did not significantly improve the model fit $\left(X^{2}=1.40, \mathrm{df}=1, \mathrm{p}=0.24\right.$ [Model

$3214])$.

\section{Results relating to Hypothesis II}

The results from the multilevel analyses assessing whether the working environment

324 (i.e. on a natural river or man-made course) was significantly associated with the need for

325 occupational recovery experienced by raft guides are presented in Table 3 . The inclusion of

326 time and river type (mixture of natural rivers and man-made courses was the reference group)

327 significantly improved the model fit $\left(X^{2}=23.33, \mathrm{df}=3, \mathrm{p}<0.001\right)$ and explained $0.24 \%$ of

328 the within subject variation of the need for occupational recovery (Model 5). Working on a

329 natural river was significantly associated with a lower need for occupational recovery $(\mathrm{B}=$ -

$33010.06, \mathrm{SE}=4.32, \mathrm{p}=0.02$ ), whereas working on a man-made course was significantly

331 associated with a greater need for occupational recovery $(B=12.45, S E=4.72, p=0.001)$.

332 These relationships did not significantly alter over time for raft guides who work on either the 333 natural rivers $(\mathrm{B}=-1.16, \mathrm{SE}=2.71, \mathrm{p}=0.67)$ or man-made courses $(\mathrm{B}=-2.03, \mathrm{SE}=2.90, \mathrm{p}$ $334=0.48$ [Model 6]). 


\section{Results relating to Hypothesis III}

With regards to Hypothesis IIIa, $0.25 \%$ of the within subject variation of the need for

occupational recovery was explained by the number of hours worked as a raft guide per

month and the type of river raft guides worked on (see Model 7). As observed with

Hypotheses I and II, monthly hours worked as a raft guide was not associated with the need

341 for occupational recovery $(B=0.00, S E=0.02, p=0.86)$, whereas working on a natural river was associated with a lower need for occupational recovery $(B=-10.06, S E=4.32, p=0.02)$ and working on a man-made course was associated with a greater need for occupational recovery $(\mathrm{B}=12.45, \mathrm{SE}=4.72, \mathrm{p}=0.01)$. The inclusion of the two moderation terms, monthly hours worked as a raft guide on a natural river and monthly hours worked on a manmade course, significantly improved the model fit $\left(X^{2}=7.41, \mathrm{df}=2, \mathrm{p}=0.02\right)$, and explained

347 a further $3.99 \%$ of the within subject variation of the need for occupational recovery experienced (see Model 8). A greater number of monthly hours worked as a raft guide on a natural river did not further reduce the need for occupational recovery experienced $(B=0.04$,

$350 \mathrm{SE}=0.06, \mathrm{p}=0.43$ ) just as a greater number of hours worked on a man-made course did not 351 increase the need for occupational recovery experienced by white-water raft guides (B = $0.16, \mathrm{SE}=0.08, \mathrm{p}=0.06)$

When testing Hypothesis IIIb, the initial step was to test direct associations between

354 the number of hours of physical leisure activity, the river type worked on and the need for 355 occupational recovery experienced. By including the monthly hours of physical leisure 356 activity and type of river worked on significantly improved the model fit $\left(X^{2}=313.06\right.$, $\mathrm{df}=4$, $\mathrm{p}<0.001$ ) but did not explain any of the within subject variation of the need for occupational recovery experienced (see Model 9). Specifically, a greater number of hours of physical 
359 leisure activity participated in per month $(\mathrm{B}=-0.10, \mathrm{SE}=0.04, \mathrm{p}=0.02)$ and working on a 360 natural river $(\mathrm{B}=-9.25, \mathrm{SE}=4.24, \mathrm{p}=0.02)$ were associated with a lower need for

361 occupational recovery, whereas working on a man-made course was associated with a greater 362 need for occupational recovery $(B=13.92, \mathrm{SE}=4.63, \mathrm{p}=0.002)$. The inclusion of the 363 interaction terms did not explain any of the within subject variation of the need for 364 occupational recovery and thus did not improve the model fit $\left(X^{2}=1.36, \mathrm{df}=2, \mathrm{p}=0.51\right.$ [see 365 Model 10]). Participating in a greater number of hours of physical leisure activity per month combined with working on a natural river was not associated with a lower need for occupational recovery $(B=-0.07, S E=0.13, p=0.60)$. Furthermore, a greater number of 368 hours of physical leisure activity combined with working on artificial man-made courses was not associated with the need for occupational recovery experienced either $(\mathrm{B}=0.06, \mathrm{SE}=$ $0.10, p=0.60)$.

\section{Discussion}

This study aimed to enhance understanding of how raft guides working in the outdoor environment on either a natural river or man-made course, their working hours and their 375 physical activity leisure time impact on their need for occupational recovery (as an indicator of fatigue). The study adopted a longitudinal study design and our results shed light on the

377 need for occupational recovery among white water rate guides and contribute to the wider 378 conceptual literature on fatigue and recovery. Importantly it also contributes new knowledge 379 around natural versus man-made outdoor activity environments on health and well-being (i.e. energy, fatigue and recovery). recovery following work, across a working season. The need for occupational recovery in this 
population (means 35.4 - 38.4) are higher than that reported in studies examining office workers (mean 32.2) (van der Starre, Robine E, Coffeng, Hendriksen, van Mechelen, \& Boot, 2013) but similar to a study on truck drivers over a two year period (means 33.2 - 37.4) (de

Croon et al., 2003). This suggests that white-water raft guides, and potentially other workers in other similar physically active outdoor activity occupations, may be at greater risk for the need of occupational recovery than other occupations. This is prior to an increase in workloads as a result of increased participation in the activity. Further research is required in similar outdoor working populations to identify the impact of occupational recovery and

391 fatigue on health and well-being outcomes.

Hypothesis Ia was rejected as working hours was negatively associated with a greater need for occupational recovery across the working. This contradicts previous findings, which identified no direct relationship between working hours and the need for occupational recovery experienced by office workers (Bos et al., 2013; Van der Hulst et al., 2006). Additionally, the negative association was unexpected, as working in the outdoor leisure 397 environment is a physically and psychologically demanding occupation (Arnould \& Price, 398 1993), making it plausible to expect that a greater number of hours worked would be 399 associated with a greater need for occupational recovery. The current study provides evidence 400 that working longer hours in a physically active, sporting occupation may not result in work401 related fatigue as observed among some sedentary occupations (e.g. van Hooff et al., 2007).

402 One possible explanation for this difference is the relationship between detachment from 403 work and work-related fatigue (Sonnentag \& Bayer, 2005). It may be that white-water raft 404 guides may not be preoccupied with work during their leisure time, however, further 405 investigation is required to unpick what work characteristics contribute to the need for 406 occupational recovery among those working in physically active sporting occupations. 

as there was a significant increase in hours worked during the middle of the season when compared to early and late. It is possible that workers who work longer hours may be

410 physically and psychologically fitter throughout the year when compared to the employees

411 who work shorter hours. Raft guides starting the season with lower baseline fitness levels, 412 may mean that they were more prone to experiencing a greater need for occupational recovery throughout the working season. Poor baseline levels of fitness can impact on the levels of fatigue experienced throughout a season, regardless of how much fitness levels improve; this seasonal pattern of fatigue has been observed among footballers (Lango-Penas,

416 Rey, Lango-Ballesteros, Dominguez \& Casais, 2013). In contrast, it is possible that raft 417 guides who work longer hours may improve their physical and psychological fitness, thus 418 protecting themselves against a greater need for occupational recovery across the season. 419 Further investigation into the physical and psychological fitness levels of the workers is 420 required to build upon the current findings.

421 As hypothesised, a greater amount of physical leisure activity was associated with a 422 lower need for occupational recovery. This supports previous literature which identified that 423 workers in sedentary occupations who participated in a greater amount of physical leisure 424 activity had a lower need for occupational recovery (Korpela \& Kinnunen, 2010; Oerlemans, 425 Bakker, \& Demerouti, 2014). The findings of the current study build upon this literature and 426 identifiy that those working in physically active occupations also benefit from engaging in 427 physical activity during their leisure time. Physical leisure activity can provide a distraction 428 from occupational demands which can reduce the amont of work-related fatigue experienced 429 by employees (Sonnentag \& Zijlstra, 2006; Korpela \& Kinnunen, 2010). This can be further 430 demonstrated by the Attention Restoration Theory (Berman, Jonides \& Kaplan, 2008). 
431 Specifically, although aspects of a physically active occupation may overlap with physical 432 leisure activity, the different tasks may require different cognitive resources, therefore 433 allowing for the replenishment of resources utilised during the working day. However, this relationship did not significantly change across the working season.

435 This suggests that engaging in physical leisure activities can have a positive effect by 436 reducing work-related fatigue. This is contrary to previous evidence which suggests that 437 physical leisure activity in addition to the physical demands of working in the outdoor industry can have negative consequences on employee well-being (AAIAC, 2006; McDermott \& Munir, 2012). It is possible that workers, such as Mountain Leaders, engage in 440 physical activities which are very similar in nature to their work, thus utilising the same 441 physical and psychological resources. As there are no details on the physical activity 442 completed by raft guides, it is possible that these activities are sufficiently different from their 443 work allowing them to recover and experience less work-related fatigue. As the Need for 444 Recovery Scale measures both physical and psychological fatigue, it is not possible to unpick 445 specifically whether physical activity improves physiological, psychological and cognitive 446 health and thus reduces the level of effort required to complete daily tasks such as work 447 (Colombe \& Kramer, 2003) or whether it provides a distraction from work aiding the 448 psychological recovery from work (Sonnentag \& Bayer, 2005). Delineating whether physical 449 or psychological fatigue is more predominant may provide more insight into how physically 450 active work and physical leisure activity affect fatigue is appropriate. As there were no 451 significant differences between the amount of physical activity completed at the different 452 times of the season, it was unsurprising that there the relationship between physical leisure 453 activity and the need for occupational recovery did not alter across the working season. 
455 on had a direct effect on the need for occupational recovery following a day's work. It

456 showed that working in a natural environment could reduce the levels of need for

457 occupational recovery, whereas, working on a man-made course increased the amount of

458 need for occupational recovery. This builds on previous literature, showing that being

459 immersed in a natural, outdoor environment may aid with the recovery process (Korpela \&

460 Kinnunen, 2010). Previous research has demonstrated this with regard to physical leisure

461 activities, however, the current study extends this to the working environment. This could be

462 related to the positive effects of being in the outdoors (De Vries, Verheij, Groenewegen, \&

463 Spreeuwenberg, 2003). However, this is not the case for man-made courses which are also

464 situated in outdoor areas, such as country parks. Having concrete surroundings may reduce

465 the stimulating environment in which a river in a natural outdoor setting provides (Korpela \&

466 Kinnunen, 2010). Empirical evidence has highlighted that exercise in a natural environment,

467 as opposed to an urban setting is more likely to result in higher levels of physical and

468 psychological energy (Ryan et al., 2010). Such benefits are attributed to the social

469 experience, physical activity associated with outdoor activities, as well as the exposure to the

470 natural environment (Ryan et al., 2010). As both white-water rafting on natural rivers and

471 man-made courses involve both social interactions and physical activity, it is most likely the

472 surrounding settings which may influence the need for occupational recovery experienced by

473 white-water raft guides. The Attention Restoration Theory poses that interactions in nature

474 require fewer directed attention resources (Berman, et al., 2008), however, in both the natural

475 and man-made settings directed attention is required to negotiate the rivers, therefore this

476 explanation alone is not enough to explain the difference in the need for occupational

477 recovery observed between those working on a natural river as opposed to an artificial river. 
478 It is therefore possible that white-water raft guides working on a natural river may experience

479 a higher connectedness with nature, as their exposure is more direct, which has been

480 associated with higher levels of self-reported well-being and physical and psychological

481 energy (Cervinka et al., 2011; Nisbet et al., 2011). Alternatively, the effects may stem from an organisational level as different white-water rafting providers tend to operate on either natural rivers or man-made courses. Interestingly, a greater number of hours worked did not increase the strength of the observed relationships between river type and the need for occupational recovery as expected in Hypothesis IIIa. It is therefore possible that the environment worked in is more important 487 than the amount of time spent working in that environment. Further investigation is required to unpick the specific occupational characteristics, whether it may be the working environment or the operational structure and job demands of the providers on natural rivers, as to why working on a natural river, as opposed to man-made courses, can reduce the levels

491 of need for occupational recovery among raft guides. Similarly, a greater number of hours of physical leisure activity did not influence the 493 relationship between the type of river worked on and the need for occupational recovery as 494 hypothesised. This suggests that the benefits of physical leisure activity are separate to the 495 working environment. As it was not recorded where physical leisure activity was undertaken, 496 it is possible that the physical leisure activity undertaken may have occurred in an artificial 497 environment (e.g. a gym) or in a natural outdoor setting. As the number of hours worked in 498 the different environments did not influence the need for occupational recovery, it is possible 499 that the location of the physical activity may also be insignificant. Further investigation into 500 the effects of working location (i.e. in a natural outdoor setting or an artificial outdoor 
501 setting) and the choice of location for physical leisure activity has on the need for

502 occupational recovery is required.

\section{Limitations}

504

One limitation of the present study is that the sample was self-selecting. This relates

505 to the initial data collection during Early Season, as well as follow-up data collections during

506 Mid and Late Season. Those who believe they require a higher need for occupational

507 recovery may have been more likely to participate in this study as opposed to their peers.

508 This may mean that levels of the need for occupational recovery may be slightly inflated.

509 However, with regards to self-selecting bias and attrition, tests of difference highlighted no

510 significant differences between those who completed the follow-up surveys when compared

511 to those that did not. This suggests that the sample has maintained its level of representation

512 of the general population despite attrition.

513 Another limitation related to the sample regards the small sample of female guides

514 who participated. Although there are 220 female raft guides registered under the British

515 Canoe Union (Sport England, 2013), less than 5\% of them participated in the study. The

516 number of registered raft guides is only an estimated figure. This is because the qualification

517 of a raft guide is maintained for the duration of a valid first aid certificate, therefore, raft

518 guides who are no longer operating in Great Britain, either because they are operating abroad

519 or no longer operating as a raft guide, will remain registered. It should also be noted that due

520 to the work being seasonal, qualified raft guides who did not start work until later in the

521 season may not have been captured. Despite this, there is a strong representation of qualified 522 male raft guides.

523 Another limitation relates to the method of data collection. Self-report data relies on

524 participants providing accurate information. However, self-reported hours worked and hours 
525 of physical leisure activity have been shown to be inaccurate in some cases (Shephard, 2003).

526 Additionally, it has not been possible to determine the extent to which individuals are

527 physically active during their working day. A more sensitive measure, such as employee data

528 or daily diary data, combined with the use of physical activity devices, such as

529 accelerometers, may be more appropriate than the recall of monthly hours worked for future

530 studies. This would allow for the unpicking of the amount and intensity of physical activity

531 conducted during a working day as well as some duties undertaken by white-water raft guides

532 may not be physical in nature. However, the self-report survey design was the most

533 appropriate design for the current study which aimed to collect data from a large sample from

534 a geographically diverse population. Furthermore, the present research is the first study to

535 examine the need for occupational recovery among those working in a physically active,

536 sporting occupation. It was therefore important to note the number of hours worked in a

537 physically active occupation as opposed to measuring the specific number of hours of

538 physical activity during the working day.

\section{Conclusions}

540 It has been identified in the present study that a greater amount of physical leisure

541 activity and working in a natural outdoor setting were associated with a lower need for

542 occupational recovery. However, working in an artificial outdoor setting was associated with

543 a greater need for occupational recovery. Interestingly, the number of hours worked was not

544 directly nor indirectly associated with the need for occupational recovery experienced by

545 white-water raft guides. Future research should focus on strategies to protect against work-

546 related fatigue. This could include creating working environments which reflect a more

547 natural setting, for example, planting shrubbery to reduce the amount of visible concrete. The 
548 findings of the current study are not limited to white-water raft guides but may also be

549 applicable to workers in other similar physically active outdoor activity occupations.

550 Acknowledgements

551 We are grateful to the English White-Water Rafting Committee for their cooperation

552 in this work. We would also like to thank Dr Ian Taylor for his advice and guidance regarding 553 the statistical analyses.

554 
556 Adventure Activities Industry Advisory Committee [AAIAC]. (2006). Surviving a career in $557 \quad$ adventure activities.

558 Arnould, E. J., \& Price, L. L. (1993). River magic: Extraordinary experience and the 559 extended service encounter. Journal of Consumer Research, 24-45.

560 Baron, R. M., \& Kenny, D. A. (1986). The moderator-mediator variable distinction in social 561 psychological research: Conceptual, strategic, and statistical considerations. Journal of $562 \quad$ Personality and Social Psychology, 51(6), 1173.

563 Beckers, D., van der Linden, D., Smulders, P., Kompier, M., van Veldhoven, M., \& van 564 565 566

567 Berman, M. G., Jonides, J., \& Kaplan, S. (2008). The cognitive benefits of interacting with 568 nature. Psychological Science, 19(12), 1207-1212.

569 Bos, J. T., Donders, Nathalie Charlotte Gerarda Maria, Schouteten, R. L. J., \& Van der 570 Gulden, Joost Willem Johannes. (2013). Age as a moderator in the relationship between 571 work-related characteristics, job dissatisfaction and need for recovery. Ergonomics, $572 \quad$ 56(6), 992-1005.

573 British Canoe Union [BCU].White water rafting homepage. (2015) Retrieved on 01/06/2015 574 from http://bcu.org.uk/our-sport/white-water-rafting/

575 Cervinka, R., Röderer, K., \& Hefler, E. (2011). Are nature lovers happy? On various 576 indicators of well-being and connectedness with nature. Journal of Health Psychology, 577 DOI: $10.1177 / 1359105311416873$. 
578 Colombe, S., \& Kramer, A. F. (2003). Fitness effects on the cognitive function of older 579 adults: a meta-analytic study. Psychological Science, 14(2), 125-130.

580 de Croon, E. M., Sluiter, J. K., \& Frings-Dresen, M. H. (2003). Need for recovery after work 581 predicts sickness absence: A 2-year prospective cohort study in truck drivers. Journal of $582 \quad$ Psychosomatic Research, 55(4), 331-339.

583 de Vries, J. D., Claessens, B. J., van Hooff, M. L., Geurts, S. A., van den Bossche, Seth NJ, 584 \& Kompier, M. A. (2015). Disentangling longitudinal relations between physical 585 activity, work-related fatigue, and task demands. International Archives of Occupational $586 \quad$ and Environmental Health, 1-13.

587 De Vries, S., Verheij, R. A., Groenewegen, P. P., \& Spreeuwenberg, P. (2003). Natural 588 environments-healthy environments? an exploratory analysis of the relationship between 589 greenspace and health. Environment and Planning A, 35(10), 1717-1732.

590 Dierdorff, E. C., \& Ellington, J. K. (2012). Members matter in team training: Multilevel and 591 longitudinal relationships between goal orientation, Self-Regulation, and team outcomes. 592 Personnel Psychology, 65(3), 661-703.

593 European Outdoor Group. (2013). Market research. Retrieved on 01/06/2015 from 594 http://www.europeanoutdoorgroup.com/market-research

595 Hill, P. W., \& Goldstein, H. (1998). Multilevel modeling of educational data with cross596 classification and missing identification for units. Journal of Educational and Behavioral $597 \quad$ Statistics, 23(2), 117-128.

598 Hug, S. M., Hartig, T., Hansmann, R., Seeland, K., \& Hornung, R. (2009). Restorative 599 qualities of indoor and outdoor exercise settings as predictors of exercise frequency. $600 \quad$ Health \& Place, 15(4), 971-980. 
601 International Rafting Federation [IRF]. (2015). What is the IRF? Retrieved on 01/06/2015 602 from http://www.internationalrafting.com/about/irf/

603 Jansen, N., Kant, I., van Amelsvoort, L., Nijhuis, F., \& van den Brandt, P. (2003). Need for 604 recovery from work: Evaluating short-term effects of working hours, patterns and 605 schedules. Ergonomics, 46(7), 664-680.

606 Kant, I. J., Bultmann, U., Schroer, K. A., Beurskens, A. J., Van Amelsvoort, L. G., \& Swaen, 607 G. M. (2003). An epidemiological approach to study fatigue in the working population: 608 The maastricht cohort study. Occupational and Environmental Medicine, 60 Suppl 1, 609 i32-9.

610 Korpela, K., \& Kinnunen, U. (2010). How is leisure time interacting with nature related to 611 the need for recovery from work demands? testing multiple mediators. Leisure Sciences, 612 33(1), 1-14.

613 Lango-Penas, C., Rey, E., Lango-Ballesteros, J., Dominguez, E., \& Casais, L. (2013).

614 Seasonal variations in body composition and fitness parameters according to individual 615 percentage of training completion in professional soccer players: original research $616 \quad$ article. International SportsMed Journal, 14(4), 205-215.

617 Lüdtke, O., Robitzsch, A., Trautwein, U., \& Kunter, M. (2009). Assessing the impact of 618 learning environments: How to use student ratings of classroom or school characteristics 619 in multilevel modeling. Contemporary Educational Psychology, 34(2), 120-131.

620 Mallinson, T., Cella, D., Cashy, J., \& Holzner, B. (2006). Giving meaning to measure:

621 Linking self-reported fatigue and function to performance of everyday activities. Journal 622 of Pain and Symptom Management, 31(3), 229-241. 
623 Mauno, S., Kinnunen, U., \& Ruokolainen, M. (2007). Job demands and resources as

624 antecedents of work engagement: A longitudinal study. Journal of Vocational Behavior, $625 \quad 70(1), 149-171$.

626 McDermott, H., \& Munir, F. (2012). Work-related injury and ill-health among mountain

627 instructors in the UK. Safety Science, 50(4), 1104-1111. doi:10.1016/j.ssci.2011.11.014

628 Nezlk, J. B. (2001). Multilevel random coefficient analyses of event- and interval-contingent 629 data in social and personality psychology research. Personality and Social Psychology $630 \quad$ Bulletin, 27(7), 771-785.

631 Nisbet, E. K., Zelenski, J. M., \& Murphy, S. A. (2011). Happiness is in our nature: Exploring 632 nature relatedness as a contributor to subjective well-being. Journal of Happiness 633 Studies, 12(2), 303-322.

634 Oerlemans, W. G., Bakker, A. B., \& Demerouti, E. (2014). How feeling happy during off-job 635 activities helps successful recovery from work: A day reconstruction study. Work \& 636 Stress, (ahead-of-print), 1-19.

637 Outdoor Foundation. (2013). The active outdoor recreation report. Retrieved on 01/06/2015 638 from http://www.outdoorfoundation.org/research.recreation.html

639 Quené, H., \& Van den Bergh, H. (2004). On multi-level modeling of data from repeated 640 measures designs: A tutorial. Speech Communication, 43(1), 103-121.

641 Rasbash, J., Charlton, C., Browne, W. J., Healy, M., \& Cameron, B. (2009). Mlwin

642 Version 2.02. Centre for Multilevel Modelling, University of Bristol.

643 Ryan, R. M., Weinstein, N., Bernstein, J., Brown, K. W., Mistretta, L., \& Gagne, M. (2010).

644 Vitalizing effects of being outdoors and in nature. Journal of Environmental Psychology, $645 \quad 30(2), 159-168$. 
646

647

648

649

650

651

652

653

654

655

656

657

658

659

660

661

662

663

664

665

666

667

668

Shephard, R. J. (2003). Limits to the measurement of habitual physical activity by questionnaires. British Journal of Sports Medicine, 37(3), 197-206; discussion 206.

Sluiter, J. K. (1999). The influence of work characteristics on the need for recovery and experienced health: A study on coach drivers. Ergonomics, 42(4), 573-583.

Sluiter, J. K., de Croon, E. M., Meijman, T. F., \& Frings-Dresen, M. H. (2003). Need for recovery from work related fatigue and its role in the development and prediction of subjective health complaints. Occupational and Environmental Medicine, 60 Suppl 1, i62-70.

Snijders, T. A., \& Bosker, R. J. (1994). Modeled variation in two-level models. Sociological Methods \& Research, 22(3), 342-363.

Sonnentag, S., \& Zijlstra, F. R. (2006). Job characteristics and off-job activities as predictors of need for recovery, well-being, and fatigue. Journal of Applied Psychology, 91(2), 330.

Sonnentag, S., \& Bayer, U. (2005). Switching off mentally: Predictors and consequences of psychological detachment from work during off-job time. Journal of Occupational Health Psychology, 10(4), 393-414. doi:10.1037/1076-8998.10.4.393

Sonnentag, S., \& Fritz, C. (2007). The recovery experience questionnaire: Development and validation of a measure for assessing recuperation and unwinding from work. Journal of Occupational Health Psychology, 12(3), 204-221. doi:10.1037/1076-8998.12.3.204

Sparks, K., Cooper, C., Fried, Y., \& Shirom, A. (1997). The effects of hours of work on health: A meta-analytic review. Journal of Occupational and Organizational Psychology, 70(4), 391-408.

Sport England. (2013). In Iain Wilson (Ed.), RE: Research examining the work-related health of white water raft guides. Email: 
669 Van der Hulst, M., Van Veldhoven, M., \& Beckers, D. (2006). Overtime and need for 670 recovery in relation to job demands and job control. Journal of Occupational Health, 671 48(1), 11-19.

672 van der Starre, Robine E, Coffeng, J. K., Hendriksen, I. J., van Mechelen, W., \& Boot, C. R. 673 (2013). Associations between overweight, obesity, health measures and need for 674 recovery in office employees: A cross-sectional analysis. BMC Public Health, 13(1), 6751207.

676 van Hooff, M. L. M., Geurts, S. A. E., Kompier, M. A. J., \& Taris, T. W. (2007). Workdays, 677 in-between workdays and the weekend: A diary study on effort and recovery. 678 International Archives of Occupational and Environmental Health, 80(7), 599-613. 679 doi:10.1007/s00420-007-0172-5

680 Van Yperen, N. W., \& Hagedoorn, M. (2003). Do high job demands increase intrinsic 681 motivation or fatigue or both? the role of job control and job social support. Academy of 682 Management Journal, 46(3), 339-348.

683 Veldhoven, M. V., \& Broersen, S. (2003). Measurement quality and validity of the "need for 684 recovery scale". Occupational and Environmental Medicine, 60(Suppl 1), 3-9. 685 doi:10.1136/oem.60.suppl_1.i 
Table 1

688 Summary of Descriptives of Reported Variables and Correlations of the Nested Variables

\begin{tabular}{|c|c|c|c|c|c|}
\hline \multirow[t]{2}{*}{ Variable } & \multicolumn{3}{|c|}{ Mean + Standard Deviation } & \multicolumn{2}{|c|}{$\underline{\text { Correlations }}$} \\
\hline & $\begin{array}{c}\text { Early } \\
\text { Season } \\
(\mathrm{N}=126)\end{array}$ & $\begin{array}{c}\text { Mid- } \\
\text { Season } \\
(\mathrm{N}=98)\end{array}$ & $\begin{array}{c}\text { Late } \\
\text { Season } \\
(\mathrm{N}=79)\end{array}$ & 1 & 2 \\
\hline Age & $\begin{array}{c}30.13 \pm \\
9.70\end{array}$ & $\begin{array}{c}30.05 \pm \\
10.05\end{array}$ & $\begin{array}{c}31.10 \pm \\
10.65\end{array}$ & & \\
\hline Body Mass Index & $\begin{array}{c}24.68 \pm \\
3.05\end{array}$ & $\begin{array}{c}24.45 \pm \\
2.75\end{array}$ & $\begin{array}{c}24.69 \pm \\
2.86\end{array}$ & & \\
\hline Years' Experience & $\begin{array}{c}5.56 \pm \\
6.21\end{array}$ & $\begin{array}{c}5.52 \pm \\
6.10\end{array}$ & $\begin{array}{c}5.42 \pm \\
6.16\end{array}$ & & \\
\hline 1. Need for Recovery & $\begin{array}{c}34.13 \pm \\
24.22\end{array}$ & $\begin{array}{c}34.88 \pm \\
25.97\end{array}$ & $\begin{array}{c}37.86 \pm \\
26.06\end{array}$ & - & \\
\hline $\begin{array}{l}\text { 2. Monthly hours worked as } \\
\text { a raft guide }\end{array}$ & $\begin{array}{c}34.60 \pm \\
47.59\end{array}$ & $\begin{array}{l}57.71 \pm \\
66.53^{* *}\end{array}$ & $\begin{array}{c}16.11 \pm \\
35.26\end{array}$ & 0.06 & - \\
\hline $\begin{array}{l}\text { 3. Monthly hours of physical } \\
\text { leisure activity }\end{array}$ & $\begin{array}{c}27.92 \pm \\
25.54\end{array}$ & $\begin{array}{c}29.63 \pm \\
31.74\end{array}$ & $\begin{array}{c}34.65 \pm \\
41.66\end{array}$ & $\begin{array}{c}- \\
0.09\end{array}$ & 0.02 \\
\hline
\end{tabular}

Sex

Male

$114 \quad 90 \quad 71$

(90.48) (91.84) (89.87)

Female

$12(9.52) \quad 8(8.16) \quad 8(10.13)$

Highest Qualification

Trainee Raft Guide

$13 \quad 9(9.18) \quad 7(8.86)$

(10.32)

Level 1 Site Specific Raft

58

46

38

Guide

(46.03) (46.94) (48.10)

Level 2 Unrestricted Raft

29

20

Guide

(23.02)

(23.47)

Level 3 Trip Leader

15

$12 \quad 7(8.86)$

(11.90)

(12.24)

Level 4 Raft Coach

5 (3.97)

$4(4.08)$

4 (5.06)

Level 5 Senior Raft Coach

$6(4.76) \quad 4(4.08) \quad 3(3.80)$ 


\begin{tabular}{|c|c|c|c|}
\hline \multicolumn{4}{|l|}{ Employment Status } \\
\hline \multirow[t]{2}{*}{ Full-Time } & 54 & 42 & 32 \\
\hline & $(42.86)$ & $(42.86)$ & $(40.51)$ \\
\hline \multirow[t]{2}{*}{ Part-Time } & 17 & 16 & 12 \\
\hline & (13.49) & (16.33) & (15.19) \\
\hline \multirow[t]{2}{*}{ Freelance } & 47 & 37 & 30 \\
\hline & $(37.30)$ & $(37.76)$ & $(37.97)$ \\
\hline Other & $8(6.34)$ & $3(3.06)$ & $5(6.33)$ \\
\hline \multicolumn{4}{|l|}{ River Type Worked On } \\
\hline \multirow[t]{2}{*}{ Natural River } & 51 & 36 & 28 \\
\hline & $(40.48)$ & (36.73) & $(35.44)$ \\
\hline Natural River and Man- & 41 & 33 & 29 \\
\hline Made Courses & (32.54) & (33.67) & $(36.71)$ \\
\hline \multirow[t]{2}{*}{ Man-Made Courses } & 34 & 29 & 22 \\
\hline & (26.98) & (29.59) & $(27.85)$ \\
\hline
\end{tabular}




\section{Table 2}

693 Coefficients from the empty model and the model including covariates

\begin{tabular}{lcccc}
\hline Variables & \multicolumn{2}{c}{ Empty Model } & & \multicolumn{2}{c}{ Model Including Covariates } \\
\cline { 5 - 5 } & Estimation & SE & Estimation & SE \\
\hline Intercept & 34.63 & 2.01 & 34.62 & 2.01 \\
Age $_{\text {CGM }}$ & & & -0.03 & 0.25 \\
Body Mass Index $_{\text {CGM }}$ & & & 0.19 & 0.69 \\
Years' Experience $_{\text {CGM }}$ & & & -0.08 & 0.38 \\
$2 \times$ log & & 2715.11 & & 2714.94 \\
$X^{2}$ & & & & 0.17 \\
Df & & & & 3 \\
Level 1 Variation & 237.33 & 25.14 & 237.26 & 25.14 \\
Level 2 Variation & 396.18 & 64.55 & 395.74 & 64.50 \\
\hline
\end{tabular}

$694 * \mathrm{p}<.05 * * \mathrm{p}<.01$ 
696 Results from Multilevel Analyses relating to Hypotheses Ia, Ib and II

\begin{tabular}{|c|c|c|c|c|c|c|c|c|c|c|c|c|}
\hline \multirow{5}{*}{$\underline{\text { Variable }}$} & \multicolumn{4}{|c|}{ Hypothesis Ia: } & \multicolumn{4}{|c|}{ Hypothesis Ib: } & \multicolumn{4}{|c|}{ Hypothesis II: } \\
\hline & \multicolumn{4}{|c|}{$\underline{\text { Hours worked as a Raft Guide }}_{\mathrm{CWC}} \underline{\text { as IV1 }}$} & \multicolumn{4}{|c|}{$\underline{\text { Hours of Physical Leisure }}_{\text {CwC Activity as IV1 }}$} & \multirow{2}{*}{\multicolumn{4}{|c|}{$\frac{\text { Natural River as IV1 and Man-Made Course }}{\text { as IV2 }}$}} \\
\hline & & & & & & & & & & & & \\
\hline & \multicolumn{2}{|c|}{ Model 1} & \multicolumn{2}{|c|}{ Model 2} & \multicolumn{2}{|c|}{ Model 3} & \multicolumn{2}{|c|}{ Model 4} & \multicolumn{2}{|c|}{ Model 5} & \multicolumn{2}{|c|}{ Model 6} \\
\hline & Estimation & SE & Estimation & SE & Estimation & SE & Estimation & SE & Estimation & SE & Estimation & SE \\
\hline Intercept & 33.80 & 2.19 & 33.17 & 2.17 & 33.49 & 2.16 & 33.36 & 2.17 & 34.49 & 3.32 & 33.68 & 3.55 \\
\hline Time & 1.10 & 1.16 & 2.36 & 1.22 & 1.77 & 1.38 & 1.78 & 1.36 & 0.96 & 1.15 & 1.96 & 1.93 \\
\hline IV1 & 0.00 & 0.02 & $-0.12 *$ & 0.05 & $-0.09 *$ & 0.04 & $-0.16^{*}$ & 0.07 & $-10.06 *$ & 4.32 & -9.13 & 4.78 \\
\hline IV2 & & & & & & & & & $12.45^{* *}$ & 4.72 & $14.10^{* *}$ & 5.28 \\
\hline Time*IV1 & & & $0.12^{* *}$ & 0.04 & & & -0.08 & 0.07 & & & -1.16 & 2.71 \\
\hline Time*IV2 & & & & & & & & & & & -2.03 & 2.90 \\
\hline $2 \times \log$ & & 2714.21 & & 2705.92 & & 2426.43 & & 2425.03 & & 2691.78 & & 2691.28 \\
\hline$x^{2}$ & & 0.90 & & $8.29 *$ & & $288.68 * *$ & & 1.40 & & $23.33^{* *}$ & & 0.50 \\
\hline Df & & 2 & & 1 & & 2 & & 1 & & 2 & & 2 \\
\hline Level 1 & 236.82 & 25.09 & 230.22 & 24.39 & 240.43 & 28.22 & 236.03 & 27.76 & 236.75 & 25.05 & 235.98 & 24.97 \\
\hline Variation & & & & & & & & & & & & \\
\hline Level 2 & 394.33 & 64.29 & 384.42 & 62.63 & 372.45 & 63.74 & 378.33 & 64.21 & 312.31 & 53.95 & 312.91 & 53.98 \\
\hline Variation & & & & & & & & & & & & \\
\hline
\end{tabular}


699 Results from Multilevel Analyses relating to Hypothesis III

700

\begin{tabular}{|c|c|c|c|c|c|c|c|c|}
\hline \multirow[t]{3}{*}{ Variables } & \multicolumn{4}{|c|}{$\begin{array}{c}\text { Monthly hours worked as a raft guide } \\
\text { IV }\end{array}$} & \multicolumn{4}{|c|}{$\begin{array}{c}\text { Monthly hours worked of physical leisure } \\
\text { activity }{ }_{\text {cwc }} \text { as the IV }\end{array}$} \\
\hline & \multicolumn{2}{|c|}{ Model 7} & \multicolumn{2}{|c|}{ Model 8} & \multicolumn{2}{|c|}{ Model 9} & \multicolumn{2}{|c|}{ Model 10} \\
\hline & Estimation & SE & Estimation & SE & Estimation & SE & Estimation & SE \\
\hline Intercept & 34.47 & 3.33 & 34.23 & 3.32 & 33.44 & 3.26 & 33.39 & 3.26 \\
\hline Time & 0.98 & 1.16 & 1.28 & 1.14 & 1.64 & 1.37 & 1.73 & 1.37 \\
\hline IV & 0.00 & 0.02 & -0.00 & 0.05 & $-0.10 * *$ & 0.04 & -0.12 & 0.09 \\
\hline Natural River & $-10.06 *$ & 4.32 & $-10.03^{*}$ & 4.32 & $-9.25 *$ & 4.24 & $-9.52 *$ & 4.25 \\
\hline Man-Made Courses & $12.45^{* *}$ & 4.72 & $12.45^{* *}$ & 4.72 & $13.92 * *$ & 4.63 & $13.86^{*}$ & 4.63 \\
\hline IV*Natural River & & & 0.04 & 0.06 & & & -0.07 & 0.13 \\
\hline IV*Man-Made Course & & & -0.16 & 0.08 & & & 0.06 & 0.10 \\
\hline $2 \times \log$ & & 2691.75 & & 2684.34 & & 2402.05 & & 2400.69 \\
\hline$X^{2}$ & & $23.36^{* *}$ & & $7.41^{*}$ & & $313.06^{* *}$ & & 1.36 \\
\hline $\mathrm{df}$ & & 4 & & 2 & & 4 & & 2 \\
\hline Level 1 Variation & 236.72 & 25.05 & 227.22 & 24.05 & 241.57 & 28.31 & 239.43 & 28.30 \\
\hline Level 2 Variation & 312.29 & 53.95 & 316.15 & 53.856 & 282.46 & 52.58 & 283.29 & 52.60 \\
\hline
\end{tabular}

701

$* \mathrm{p}<0.05 * * \mathrm{p}<0.01$ 